\title{
Depressive Symptoms among Patients with Epilepsy Attending Adare General Hospital, Hawassa Ethiopia: Cross-sectional Study
}

Bereket Duko $^{1 *}$, Abebe Tamirat ${ }^{1}$, Tariku Mengesha ${ }^{2}$ and Mebratu Mathewos ${ }^{3}$

${ }^{1}$ College of Medicine and Health Sciences, Hawassa University, Hawassa, Ethiopia

${ }^{2}$ Saint Peter Specialized Hospital, Addis Ababa, Ethiopia

${ }^{3}$ Hawassa University Comprehensive Specialized Hospital, Hawassa, Ethiopia

\begin{abstract}
Background: Depression is highly prevalent in epileptic patients. It was the most frequent co-morbid psychiatric disorder in patients with epilepsy. Its prevalence had estimated to range between $20-50 \%$ of patients. There are limited studies which showed the magnitude of depression among epileptic patient in sub-Saharan Africa. The aim of the study was to assess the prevalence of depressive symptom and associated factors among patients with epilepsy attending Adare General Hospital, Hawassa, Ethiopia, 2017.
\end{abstract}

Methods: Institution based cross sectional study design was conducted among 114 patients with epilepsy who were selected by using convenience sampling technique. Data was collected through face to face interviews by trained data collectors using patient health questionnaire item nine (PHQ-9). Data was entered and analysed by using SPSS Version 22. Level of significance was determined by using $p<0.05$.

Results: A total of 114 participants were recruited for study. The mean age of respondents was $27.60 \pm(S D=7.91)$ years. The prevalence of unrecognized depressive symptom was $34.2 \%$. Age $[18-24$ year (AOR=6.89, $95 \% \mathrm{Cl}(1.29$, 12.78)], Poor social support [AOR=7.5, 95\% Cl (1.89, 9.79)], Sex (Female (AOR=7.54, 95\% Cl $(1.34,12.42)$ and being unemployed $[\mathrm{AOR}=3.09,95 \% \mathrm{Cl}(1.19,10.51)$ have statistically significant association with unrecognized depressive symptom.

Conclusion: Overall the prevalence of depression was found to be high (34.2\%). Age, poor social support, being female, and unemployment were factors associated with depressive symptom. The current finding emphasized need for proper psychiatric evaluation for overall management of patient with epilepsy. Further study is recommended to identify associated factors of depressive symptoms.

Keywords: Unrecognized depressive symptom; Epileptic patients

\section{Background}

Depression is the most frequent psychiatric co-morbidity in people with epilepsy with life-time prevalence rates ranging from $30 \%$ to $35 \%$ [1]. In patients with medically intractable, or only partially controlled epilepsy, rates of depression range from $20 \%$ to $55 \%$, while in patients with controlled epilepsy, rates range from $3 \%$ to $9 \%$ [2].

The incidence of depressive disorder in epilepsy ranges from $11 \%$ to approximately $62 \%$ [3]. It was estimated that the 12 -month prevalence of depression was $7.4 \%$ [ 4 ], with a lifetime prevalence of up to $16.6 \%$ in adults over 18 years [5].

According to different world wide literature the magnitude of depression among adult epileptic people had a varied figure. Prevalence of depressive symptom accounted $20 \%$ in Thailand, $25 \%$ in India, $24 \%$ to $32 \%$ in Brazil, $38 \%$ in china $60 \%$ in Pakistan and $25.5 \%$ in Egypt [6]. In addition, one study conducted in Addis Ababa, Ethiopia, showed the prevalence of depressive symptom among epileptic patient 32.8\% [7].

Co-morbid depression can have significant physical, social and financial consequence, including increased drug use, poor quality of life, social disability and mortality [3]. Recognition and treatment of depression was an important consideration in improving quality of life in epilepsy [8]. The risk factor for suicide among epileptic patient includes psychiatric co-morbidity of depression. Depression had also been found to be the most important factor associated with reduced quality of life in epileptic patient and cause severe diagnostic, therapeutic and social problem [2].

There are limited studies which showed the magnitude of depression among epileptic patient in sub-Saharan region. The aim of this study to identify the prevalence of depression in epileptic patient and its associated factor among epileptic patient attending in Adare Hospital, Hawassa, Ethiopia.

\section{Methods}

Study setting and design: Institution based cross-sectional study was conducted in April 2017. Hawassa city is found in the south of Ethiopia which is $275 \mathrm{KM}$ from the capital city of Ethiopia, Addis Ababa. Adare Hospital is established in Hawassa city in 1962 as a health centre; at the beginning the health centre provides health care service for 2695 people. In 2011 the then health centre upgraded to general hospital. According to 2016 data, psychiatry outpatient department gives service for 1188 epileptic patients annually. 114 patients were recruited for the study. Study participants were included using convenience sampling technique. A total of 114 patients with the diagnosis of epilepsy were included in the study.

*Corresponding author: Dr Bereket Duko, Faculty of Health Sciences, College of Medicine and Health Sciences, Hawassa University, Hawassa, Ethiopia, Tel: 251462205311; E-mail:waktasuabe@gmail.com

Received: February 23, 2018; Accepted: April 05, 2018; Published: April 15, 2018

Citation: Duko B, Tamirat A, Mengesha T, Mathewos M (2018) Depressive Symptoms among Patients with Epilepsy Attending Adare General Hospital, Hawassa Ethiopia: Cross-sectional Study. J Psychiatry 21: 447. doi:10.4172/2378 5756.1000447

Copyright: (c) 2018 Duko B, et al. This is an open-access article distributed unde the terms of the Creative Commons Attribution License, which permits unrestricted use, distribution, and reproduction in any medium, provided the original author and source are credited 
Citation: Duko B, Tamirat A, Mengesha T, Mathewos M (2018) Depressive Symptoms among Patients with Epilepsy Attending Adare General Hospital, Hawassa Ethiopia: Cross-sectional Study. J Psychiatry 21: 447. doi:10.4172/2378-5756.1000447

Page 2 of 4

\section{Inclusion and exclusion criteria}

All adult Patients with epilepsy who attend in Adare general hospital with age $\geq 18$ years were included in the sample and who were seriously ill and have problems of communication were excluded problem the sample.

\section{Data collection instruments}

Demographic variables were collected using semi-structured questionnaire. Social support related issue was assessed by Oslo social support scale. Oslo three items social support scale (OSS-3) provides a brief measure of social support and functioning and it is considered to be one of the best predictors of mental health. It covers different fields of social support by measuring the number of people the respondent feels close to, the interest and concern shown by others, and the ease of obtaining practical help from others. In order to score OSS-3, total scores are calculated by adding up the raw scores for each item. The sum of the raw scores has a range from 3-14 [9].

Depression was measured by using patient health questionnaire item nine (PHQ-9) which is a 9 item depression screening and diagnostic questionnaire for major depressive disorder based on DSMIV criteria with sensitivity $86 \%$ and specificity $67 \%$. ThePHQ-9 appears to be a reliable and valid instrument that may be used to diagnose MDD among Ethiopian adults [10].

\section{Data processing and analyses}

The Statistical Program for Social Science (SPSS version 22) was used for data analyses. Socio-demographic (age, sex, and marital status, areas of residence, religion, and education) and clinical factors was analysed and presented by using words, tables and charts.

\section{Ethical consideration}

Ethical clearance for this study was obtained from the Research and Ethics Review Committee of College of Medicine and Health Sciences, Hawassa University. Permission letter was obtained and submitted to Adare Hospital. Study participants were informed about their rights to interrupt the interview at any time and written informed consent was obtained from each study participants. Confidentiality was maintained at all levels of the study. Subjects who were found to have moderate to severe depressive symptoms, had poor social support were treated at clinic.

\section{Results}

\section{Socio-economic and demographic characteristics}

A total of 114 clients were participated in the study giving a response rate of $100 \%$. The mean age of the clients was $27.60 \pm(\mathrm{SD}=7.91)$ years. There were $75(65.8 \%)$ were female, 66 (57.9\%) were married, 82(71.9\%) were Protestant by religion, $45(39.5 \%)$ private employer, $65(57.0 \%)$ were Sidama by ethnicity, $47(41.2 \%)$ of the respondents were secondary school completed and 60 (52.6\%) of clients have good social support (Table 1).

When we see the educational distribution of patient with epilepsy; among 114 epileptic patient $13(11.4 \%)$ of them were unable to write and read, 37 (32.5\%) were primary school complete, 47 (41.2\%) were secondary and preparatory school complete, and the rest $17(14.9 \%)$ were college/University complete (Figures 1-3).
Table 1: Socio-demographic characteristics of patient with epilepsy attending Adare Hospital, Hawassa, Ethiopia $(n=114)$.

\begin{tabular}{|c|c|c|c|}
\hline \multicolumn{2}{|c|}{ Variable } & \multirow{2}{*}{$\begin{array}{c}\text { Frequency } \\
39\end{array}$} & \multirow{2}{*}{$\begin{array}{c}\text { Percentage } \\
34.2\end{array}$} \\
\hline Sov & Male & & \\
\hline sex & Female & 75 & 65.8 \\
\hline \multirow{2}{*}{ Marital status } & Single & 48 & 42.1 \\
\hline & Married & 66 & 57.9 \\
\hline \multirow{4}{*}{ Ethnic background } & Sidama & 65 & 57.0 \\
\hline & Wolaita & 25 & 21.9 \\
\hline & Oromo & 10 & 8.8 \\
\hline & Others & 14 & 12.3 \\
\hline \multirow{3}{*}{ Occupation } & Government employee & 29 & 25.4 \\
\hline & Private employee & 45 & 39.4 \\
\hline & Jobless & 40 & 35.2 \\
\hline \multirow{3}{*}{ Monthly income } & $<750$ Ethiopian Birr & 51 & 44.7 \\
\hline & 750-1200 Ethiopian Birr & 26 & 22.8 \\
\hline & $>1200$ Ethiopian Birr & 37 & 32.5 \\
\hline
\end{tabular}

\section{Age of the participant}

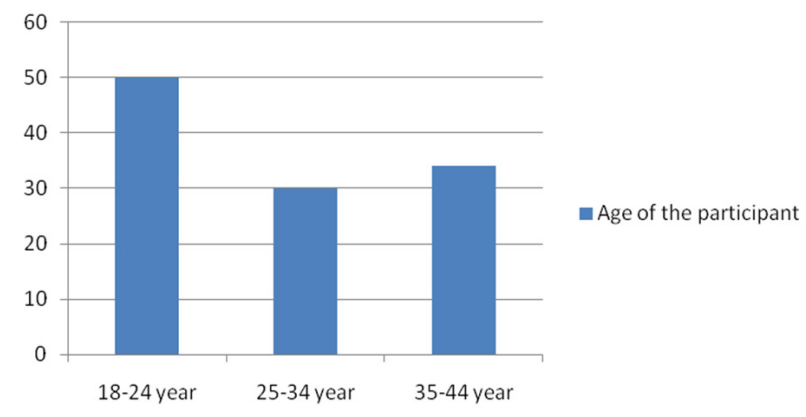

Figure 1: Age of respondant attending in Adare hospital, Hawassa, Ethiopia $(n=114)$.

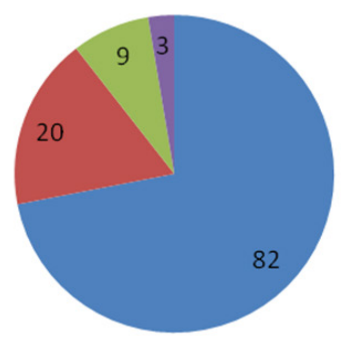

- Protestant

- Orthodox

Muslim

- Catholic

Figure 2: Religious status of the respondant attending Adare hospital, Hawassa, Ethiopia.

\section{Social support status of patient with epilepsy}

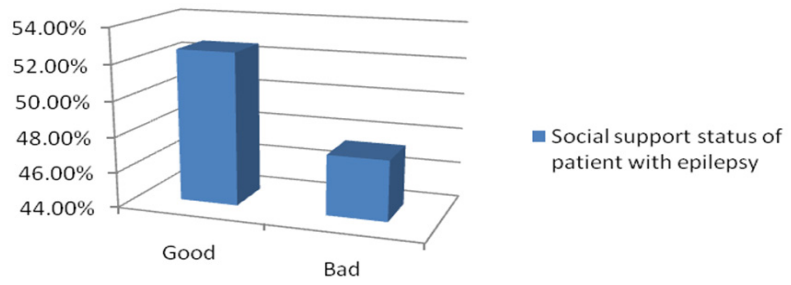

Figure 3: Social support status of patient with epilepsy attending Adare hospital, Hawassa, Ethiopia. 
Citation: Duko B, Tamirat A, Mengesha T, Mathewos M (2018) Depressive Symptoms among Patients with Epilepsy Attending Adare General Hospital, Hawassa Ethiopia: Cross-sectional Study. J Psychiatry 21: 447. doi:10.4172/2378-5756.1000447

Page 3 of 4

\begin{tabular}{|c|c|c|c|c|c|c|}
\hline \multirow{2}{*}{\multicolumn{2}{|c|}{ Variables }} & \multirow{2}{*}{$\begin{array}{c}\text { Depressive Symptom } \\
\text { Yes }\end{array}$} & \multirow[b]{2}{*}{ No } & \multirow[t]{2}{*}{ P-value } & \multirow[t]{2}{*}{ COR (95\% Cl) } & \multirow[t]{2}{*}{ AOR $(95 \% \mathrm{Cl})$} \\
\hline & & & & & & \\
\hline \multirow{2}{*}{ Sex } & Male & 31 & 8 & 0.02 & 1 & 1 \\
\hline & Female & 44 & 31 & & $2.73(1.10,6.73)$ & $1.34(1.10,12.42)$ \\
\hline \multirow{3}{*}{ Age } & $18-24$ & 20 & 30 & 0.01 & $18.68(2.27,6.52)$ & $6.89(1.29,12.78)$ \\
\hline & $25-34$ & 26 & 4 & & $1.11(0.32,3.89)$ & $1.48(0.20,11.05)$ \\
\hline & $35-44$ & 29 & 5 & & 1 & 1 \\
\hline \multirow{2}{*}{ Marital status } & Unmarried & 20 & 28 & 0.07 & $7.00(2.94,16.62)$ & $3.32(0.61,18.02)$ \\
\hline & Married & 55 & 11 & & 1 & 1 \\
\hline \multirow{3}{*}{ Occupational status } & Government & 24 & 5 & 0.01 & 1 & 1 \\
\hline & Non-government & 39 & 6 & & $0.73(0.20,2.68)$ & $0.16(0.01,1.90)$ \\
\hline & Jobless & 12 & 28 & & $11.20(3.45,36.34)$ & $3.09(1.19,10.51)$ \\
\hline \multirow{3}{*}{$\begin{array}{l}\text { Monthly income in } \\
\text { Ethiopian Birr }\end{array}$} & $<750$ (under poverty) & 19 & 32 & 0.2 & $7.73(0.15,19.08)$ & $4.27(0.22,81.09)$ \\
\hline & $750-1200$ (Medium income) & 22 & 4 & & $2.06(0.42,10.10)$ & $1.72(0.14,20.70$ \\
\hline & $>1200$ (High income) & 34 & 3 & & 1 & 1 \\
\hline \multirow{2}{*}{ Social Support } & Poor & 22 & 32 & 0.001 & $11.01(4.22 .28 .67)$ & $7.50(3.89,9.79)$ \\
\hline & Good & 53 & 7 & & 1 & 1 \\
\hline
\end{tabular}

Table 2: Multivariate logistic analysis result of patient with epilepsy attending Adare hospital, Hawassa, SNNPR, Ethiopia ( $n=114$ ).

The prevalence of unrecognized depressive symptom and its associated factors

According to PHQ-9, 39 (34.2\%) study subjects were identified as having depressive symptom. According to the result from multivariate analysis; Age [18-24 year $(\mathrm{AOR}=6.89,95 \% \mathrm{CI}(1.29,12.78)]$, Poor social support $[\mathrm{AOR}=7.5,95 \% \mathrm{CI}(1.89,9.79)]$, Sex (Female $(\mathrm{AOR}=7.54,95 \%$ CI $(1.34,12.42)$ and being unemployed [AOR $=3.09,95 \%$ CI $(1.19$, 10.51) were factors statistically Significant with depressive symptoms at $p$ value $<0.05$ (Table 2 ).

\section{Discussion}

The prevalence of depression in patient with epilepsy in Adare hospital was $34.2 \%$. This finding is consistent to the study carried out in USA [11], Egypt [12,13] and Ethiopia. On the other hand, the finding is higher than study conducted in Brazil, in India [14], Morocco [15], and in Ethiopia [16]. The current findings was lower than a study conducted in Poland [17], in India [14], in Pakistan [18], in Iran [19], in Gaza strip, in Morocco, in South east Nigeria [20] and in the North West Ethiopia's [21,22]. The difference might be due to the difference in data collection tool, socio-demographic characteristics and sample size.

Compared to female, being female was 7.5 more likely to experience depressive symptom. This finding is consistent with reports in Nigeria, and in Ethiopia. The reason might be, in women, the effect of estrogens on hippocampus synaptogenesis was parallel to those of antidepressants. Moreover, loss of estrogen appears to be a critical contributor to the etiology of depressive disorders. The increased incidence of depression observed in women with epilepsy might therefore reflect a hormonal deficiency state because epilepsy is frequently associated with defects in reproductive function.

Regarding age distribution, epileptic patient in age group of $18-24$ years more likely develop depressive symptom. This finding was supported by the study conducted in Ethiopia and in Nepal. The possible reason might be the participant on this age group want to participate on different activity with their friends but the precaution due to disease condition might cause depressive symptoms.

Having poor social support was 7.5 times more likely develop depression when compared to those who had good social support.
We lack some literatures which support this finding. These might be linked to community perception of epilepsy, it is perceived as sin and as communicable disease; this might result psychological distress.

Being jobless was significantly associated with depressive symptom. We did not get literature reviews that support this finding. However, the reason might be because of their joblessness they will not feel good and it may relate to income and poor economic status.

\section{Conclusion}

The prevalence rate of depression was $32.4 \%$. Age, sex, occupation and social support were the most important significant factors for depressive episodes. Epilepsy clinics should give more emphasis to those clients with depressive symptoms. Further research on determinants of depressive symptoms should be conducted to strengthen and broaden the current findings.

\section{Acknowledgements}

The authors acknowledge Adare General Hospital, Hawassa, Ethiopia. The authors appreciate the study participants for their cooperation in providing the necessary information and data collectors.

\section{Competing Interests}

The authors declare that they have no competing interests.

\section{Authors' Contributions}

BD conceived the study and was involved in the study design, reviewed the article, analysis, report writing and drafted the manuscript. AT, TM and MM were involved in the study design, analysis and drafted the manuscript. All authors read and approved the final manuscript.

\section{Availability of Data and Materials}

Because the sensitivity of the data, the data will not be shared publically but upon request we will avail the necessary data for concerned body.

\section{References}

1. Abiola T, Udofia O, Zakari M (2013) Psychometric properties of the 3-item Oslo Social Support scale among clinical students of Bayero University Kano Nigeria. Malaysian Journal of Psychiatry 22: 32-41. 
Citation: Duko B, Tamirat A, Mengesha T, Mathewos M (2018) Depressive Symptoms among Patients with Epilepsy Attending Adare General Hospital, Hawassa Ethiopia: Cross-sectional Study. J Psychiatry 21: 447. doi:10.4172/2378-5756.1000447

2. Adhikari AP, Ojha SP, Chapagai M, Tulachan P (2013) Prevalence of depression in patients with epilepsy: A study from Tribhuvan University- Teaching Hospital. Journal of Psychiatrists' Association of Nepal.

3. Aziz URY, Abdul WY, Rizwan T (2009) Frequency of depression in epilepsy: A hospital based study. J Ayub Med Coll Abbottabad 21: 1-3.

4. Barry JJ, Huynh N, Lembke A (2000) Depression in individuals with epilepsy. Curr Treat Option Neurol 2: 571-585.

5. Barry JJ, Anna L (2007) Ineffective disorder in epilepsy in psychiatric issues in epilepsy. A practical guide to diagnosis and treatment. Lippincott Williams and Wilkins, US

6. Berhanu BB, Berihun AD, Bewket TT, Nigusie BT (2015) Depression among people with epilepsy in North West Ethiopia: a cross-sectional institution based study. BMC Res Notes 8: 585.

7. Cramer JA, Blume D, Fanning K, Reed M, Epilepsy Impact Project Group (2004) The impact of comorbid depression on health resource utilization in a community sample of people with epilepsy. Epilepsy Behav 5: 337-342.

8. Gelaye B, Williams MA, Lemma S, Deyessa N, Bahretibeb Y, et al. (2013) Validity of the patient health questionnaire -9 for depression screening and diagnosis in East Africa. Psychiatry Res 210: 653-661.

9. Harish A, Rajdeep K (2009) Prevalence of depression in epileptic patients. Delhi Psychiatry Journal 12: 231-233.

10. Hermann BP, Seidenberg M, Bell B (2000) Psychiatric comorbidity in chronic epilepsy: identification, consequence, and treatment of major depression. Epilepsia 41: 31-41.

11. Johnson EK, Jones JE, Seidenberg M, Hermann BP (2004) The relative impact of anxiety, depression, and clinical seizure features on health-related quality of life in epilepsy. Epilepsia 45: 544-550.
12. Kanner AM, Schachter SC, Barry JJ, Hesdorffer DC, Mula M, et al. (2012) Depression and epilepsy: epidemiologic and neurologic perspectives that may explain their high comorbid occurrence. Epilepsy Behav 24: 156-168.

13. Kanner AM (2003) Depression in epilepsy: Prevalence, clinical seminology, pathogenic mechanism, and treatment. Biol Psychiatry 54: 388-398.

14. Kanner AM (2006) Depression and epilepsy: A new perspective on two closely related disorder. Epilepsy Curr 6: 141-146.

15. Kaplan HI, Sadock BJ (2003) Delirium, dementia, and amnestic and other cognitive disorder and mental disorder due to general medical condition. In: Syncopsis of psychiatry (9th edn.). Lippincott, Williams and Wilkins, Baltimore. pp: 356-360.

16. Minale TT, Tilahun BM, Andarge AA, Ashagre MA, Temitm BG, et al. (2013) Depression and anxiety disorder among epileptic people at amanuel specialized Mental Hospital, Addis Ababa, Ethiopia. BMC Psychiatry 15: 210.

17. Mohammed A (2012) Depression among epileptic patients in governmental community mental health centers in Gaza strip.

18. Onwuekwe I, Ekenze OS, Bzeala A, Ejekwuju (2009) South East Nigeria depression in patients with epilepsy in Enugu.

19. Santos IS, Tavares BF, Munhoz TN, Silva NT, Tams BD, et al. (2013) Sensitivity and specificity of the health questionnaire-9 (PHQ-9) among adults from the general population. Cad Saude Publica 29: 1533-1543.

20. Todorova K, Armaoudova M (2010) Depression disorders in epilepsy in medical university, Varna, Bulgaria. Journal of IMAB 16: 57-60.

21. WHO (2012) The world health report 200-mental health. World Health Organistaion, Geneva.

22. WHO (2013) Investigating Mental Health. World Health Organistaion, Geneva 